\title{
Temple Encyclopedia Application Based on Android (East Java Temple Case Study)
}

\section{Aplikasi Ensiklopedia Candi Berbasis Android (Studi Kasus Candi Jawa Timur)}

\author{
Sasmito Bagus Sumadyo ${ }^{1}$, Suprianto ${ }^{2}$ \\ \{ sasmitobaguss@gmail.com ${ }^{1}$, suprianto@umsida.ac.id ${ }^{2}$ \}
}

Universitas Muhammadiyah Sidoarjo, Indonesia ${ }^{1}$, Universitas Muhammadiyah Sidoarjo, Indonesia ${ }^{2}$

\begin{abstract}
The purpose from this research is to designing and to produces a mobile application of Encyclopedia which can give data information of related temple that they just visit. Research's method is using waterfall method, the technique to collecting data using seconder data technique which temple's data have been collected from book printed by Ministry of Education and Culture. Product from this research is temple's visitor can get information about temple related with mobile by scanning qrcode.
\end{abstract}

Keywords - encyclopedia, temple, mobile, qrcode.

\begin{abstract}
Abstrak. Tujuan dari penelitian ini adalah merancang dan menghasilkan sebuah aplikasi Ensiklopedia yang bersifat mobile yang dapat memberikan informasi data terkait candi yang sedang mereka kunjungi. Metode penelitian yang digunakan ialah metode waterfall, sedangkan tehnik untuk pengumpulan datanya menggunakan tehnik data sekunder, yang data candinya didapatkan dari buku terbitan Kementrian Pendidikan dan Kebudayaan. Hasil dari penelitian ini adalah pengunjung candi dapat memperoleh informasi candi terkait secara mobile dengan hanya memindahi qrcode.
\end{abstract}

Kata Kunci - ensiklopedia, candi, mobile, qrcode.

\section{Pendahuluan}

Jawa Timur merupakan sebuah provinsi dari Indonesia yang memiliki banyak sejarah akan kerajaan - kerajaan yang pernah berpusat di provinsi tersebut. Menurut Yusuf dalam bukunya yang berjudul Dinamika Islam Filipina, Burma, dan Thailand, mengatakan jika di Indonesia telah banyak berdiri candi yang memiliki ukuran dari yang kecil hingga yang besar, bahkan candi tersebut dapat ditemukan hingga ke plosok - plosok. Yusuf juka mengatakan alasannya adalah karena Indonesia sendiri pada mulanya memiliki sebuah kerajaan besar yang terkenal dan pernah berjaya pada masanya. Dalam Negarakertagama, tertulis luasan wilayah kekuasaan Majapahit yang meliputi dari pulau Jawa, hingga ke pulau Bali, Sumatera, Kalimantan, hingga sampai ke Indonesia bagian timur, termasuk Nusa Tenggara, Sulawesi, sampai dengan sebagian dari Maluku [1].

Sejarah candi masih menjadi bahan ajaran untuk siswa - siswi yang masih duduk dibangku sekolah, tentunya agar mereka tidak melupakan sejarah negaranya sendiri dan juga mengerti dengan bangunan sejarah seperti candi. Tidak lupa juga biasanya sekolah memiliki program study tour yang mengajak para siswa - siswinya untuk berkunjung ke candi - candi untuk dapat belajar langsung. Namun pada saat dilapangan, seringkali guru hanya memberikan penjelasan yang ala kadarnya saja, sehingga hal tersebut membuat para siswanya tidak tertarik untuk mendengarkan. Apalagi sering kita jumpai jika para siswa dan siswi jika melakukan study tour mereka hanya fokus untuk pengambilan gambar saja. Sering juga ditemui para siswa ataupun wisatawan yang menaiki candi - candi, menduduki candi, dan mencoret - coret candi dengan tulisan atau gambar yang tidak dibenarkan.

Identifikasi masalah yang peneliti peroleh yakni kesulitannya para wisatawan maupun pelajar dalam memperoleh informasi, wisatawan maupun pelajar membutuhkan tempat penyediaan pelayanan yang mobile dan informasi dapat dipercaya. Pada aplikasi ensiklopedia candi ini, informasi yang diperoleh itu akan berasal dari sebuah buku dari Kementrian Pendidikan dan Kebudayaan yang mungkin memiliki kesamaan dengan buku ajaran siswa di sekolah. Untuk jumlah candi yang akan dimuat didalam aplikasi hanya akan berjumlah sesuai candi yang berada di buku Candi Indonesia : Seri Jawa untuk di wilayah jawa timur yakni berjumlah 46 candi [2].

Penelitian yang sama telah dilakukan oleh Ida Bagus [3] pada museum Bali yang telah menciptakan sebuah aplikasi android dengan jaringan semantic untuk dapat menyajikan informasi deskripsi dengan memindahi qrcode juga. Menurutnya penggunaan android tersebut mampu untuk memikat perhatian pengunjung dari museum tersebut dikarenakan penyampaian informasi deskripsi di tempilkan dengan fitur yang menarik seperti fitur memindahi qrcode itu sendiri. Pada penelitiannya Ida Bagus [3] mengungkapkan jika pengunjung hanya perlu menggunakan smartphone nya untuk dapat memindahi qrcode dan mengakses informasi dari benda - benda bersejarah langsung di layer smartphone mereka. Berdasarkan itulah peneliti memiliki tujuan untuk menerapkan kemudahan memperoleh informasi tersebut tidak hanya pada benda museum saja, namun juga pada bangunan sejarah seperti candi, dengan tujuan sekali lagi yakni untuk mempermudah dan mengefesienkan baik pengunjung wisatawan atau pelajar dan 
pengelola candi juga dalam mengakses informasi mengenai candi. Untuk itu peneliti memulai menggagas sebuah ide penelitian yang berjudul "APLIKASI ENSIKLOPEDIA CANDI BERBASI ANDROID"

\section{METODE}

\section{A. Objek Penelitian}

Objek pada penelitian ini tertuju hanya pada candi yang berada di kawasan Jawa Timur, Sedyawati [2] memaparkan setidaknya 46 candi yang terdapat pada Jawa Timur, baik candi yang masih terjaga baik, tidak dikenali bentuknya maupun candi yang sudah tidak utuh lagi dan hanya meninggalkan dasaran candi. Untuk metode pengumpulan datanya menggunakan teknik data sekunder, yakni informasi mengenai candi didapatkan melalui buku karangan Sedyawati yang dicetak oleh Kementrian Pendidikan dan Kebudayaan tahun 2013.

\section{B. Analisa Perangkat Lunak}

1) Kebutuhan Perangkat Lunak

Pada analisi pengembangan aplikasi Ensiklopedia Candi ini, didapatkan beberapah kebutuhan fungsionalnya yang dapat di implementasikan, yakni:

a. Kebutuhan Fungsional

Kebutuhan fungsional yang terdapat pada platform website yang dapat diimplementasikan yaitu seperti : (1) Aplikasi website dapat menyediakan tempat pengunduhan aplikasi untuk perangkat android. (2) Aplikasi website dapat mengidentifikasi akun dari admin. (3) Aplikasi website dapat menyimpan informasi candi dan menambah gambar candi. (4) Aplikasi website dapat menerima request dari aplikasi dan mengirim informasi. Sedangkan untuk platform android kebutuhan yang dapat diimplementasikan yaitu seperti : (1) Aplikasi android dapat memindahi qrcode dan mengirim request ke aplikasi website. (2) Aplikasi android dapat menampilkan hasil request yang telah dikirimkan oleh aplikasi website. (3) Aplikasi android dapat membedakan qrcode candi dan qrcode yang bukan.

b. Kebutuhan Non-fungsional

Kebutuhan non-fungsional selanjutnya yang dapat diimplementasikan pada kedua platform aplikasi Ensiklopedia Candi yaitu aplikasi dibangun dengan user friendly, tampilan yang dibuat untuk memudahkan baik pada pengguna perangkat android maupun admin pada aplikasi website.

2) Lingkungan Implementasi Perangkat Lunak

Pada pengembangan aplikasi Ensiklopedia Candi ini, tentu menggunakan beberapa dari perangkat lunak maupun perangkat keras yang digunakan. Pada pengembangan aplikasi ini, peneliti menggunakan perangkat lunak seperti : (1) Sistem operasi windows 10. (2) Peramban google chrome. (3) Android studio. (4) XAMPP. Adapun pada perangkat keras yang digunakan peneliti, seperti : (1) Laptop dengan spesifikasi : (a) Processor AMD Ryzen 5 3500U with Radeon Vega Mobile 2.10Ghz. (b) Memori Ram sebesar 8Gb. (c) SSD berkapasitas 500Gb.

\section{Metode Pengembangan Aplikasi}

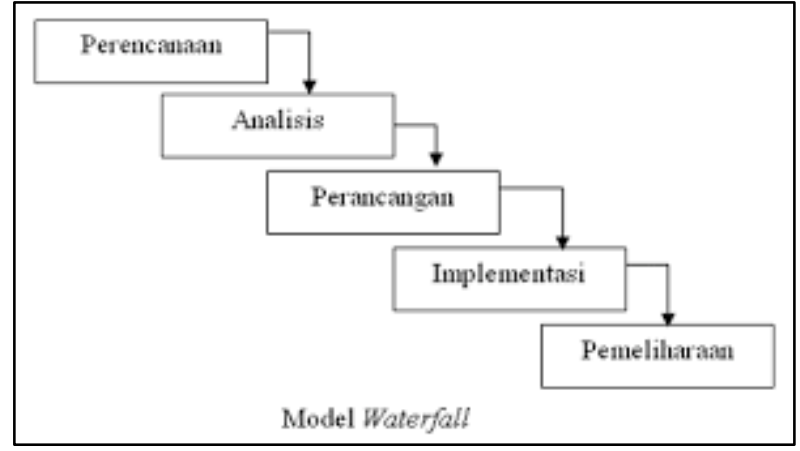

Gambar 1. Model Waterfall

Aplikasi Ensiklopedia Candi ini menggunakan metode pembangunan yang sama dengan penelitian terdahulunya yakni metode waterfall, yang merupakan model klasik namun bersifat sistematis, untuk pembangunan aplikasinya metode ini dilakukan dengan berurutan seperti dijelaskan pada Gambar 1.

\section{Diagram Alur Aplikasi}




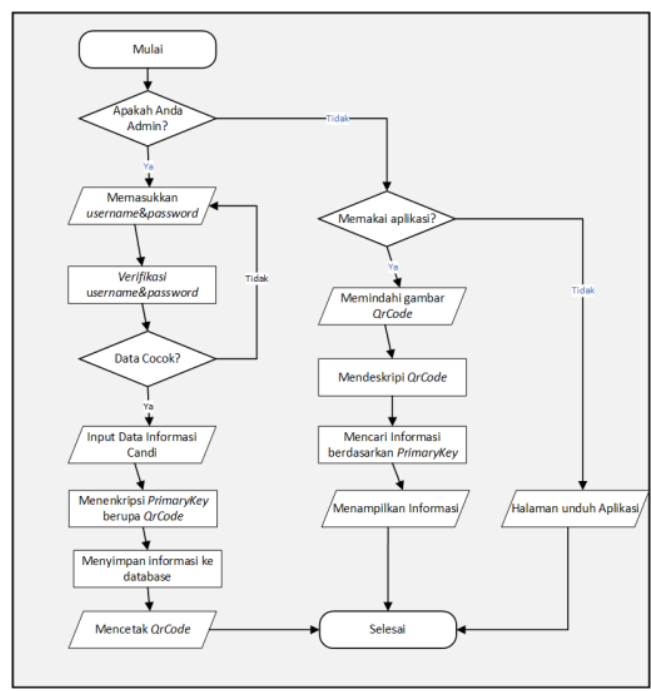

Gambar 2. Diagram Alur Aplikasi

Model alur diagram dari aplikasi Ensiklopedia Candi pada penelitian ini dapat dilihat seperti pada Gambar 2. Pada Gambar 2 telah di jelaskan alur jalannya aplikasi baik dengan menggunakan platform website maupun platform android. Pada alur diagram tersebut menjelaskan bagaimana informasi diterima dan disimpan kedalam basis data melalui platform website dan bagaimana aplikasi menerima informasi dan menampilkannya di perangkat android.

\section{E. Perancangan Antarmuka Perangkat Lunak}

Peneliti juga telah merancang desain antarmuka untuk aplikasi Ensiklopedia Candi baik untuk platform website maupun untuk platform android seperti pada Gambar 3 dan Gambar 4.

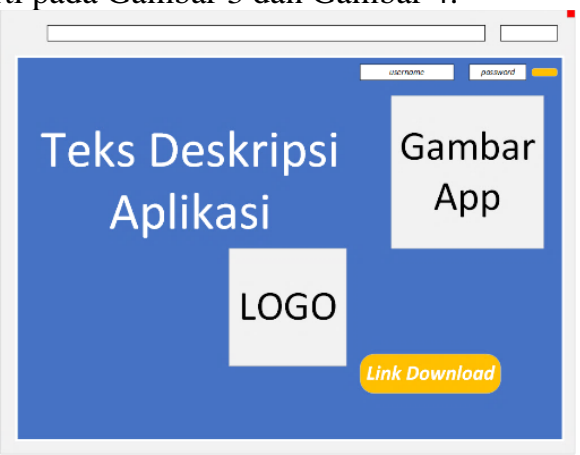

Gambar 3. Rancangan antarmuka pada landing page aplikasi website
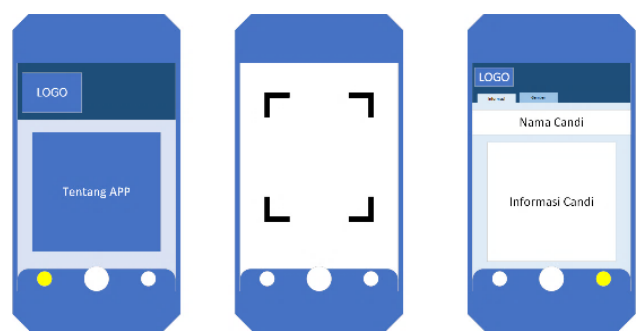

Gambar 4. Rancangan antarmuka pada aplikasi android

\section{Hasil dan Pembahasan}

\section{A. Implementasi Antarmuka Perangkat Lunak}

(1) Antarmuka perangkat lunak pada platform website.

Pada implementasi pengembangan antarmuka perangkat lunak pada platform website didapatkan beberapah halaman yang nantinya akan memudahkan dan menunjang pada pengelolaan informasi terkait candi, diantaranya ialah : 
Procedia of Engineering and Life Science Vol. 1. No. 1 March 2021

Seminar Nasional \& Call Paper Fakultas Sains dan Teknologi (SENASAINS 1st)

Universitas Muhammadiyah Sidoarjo

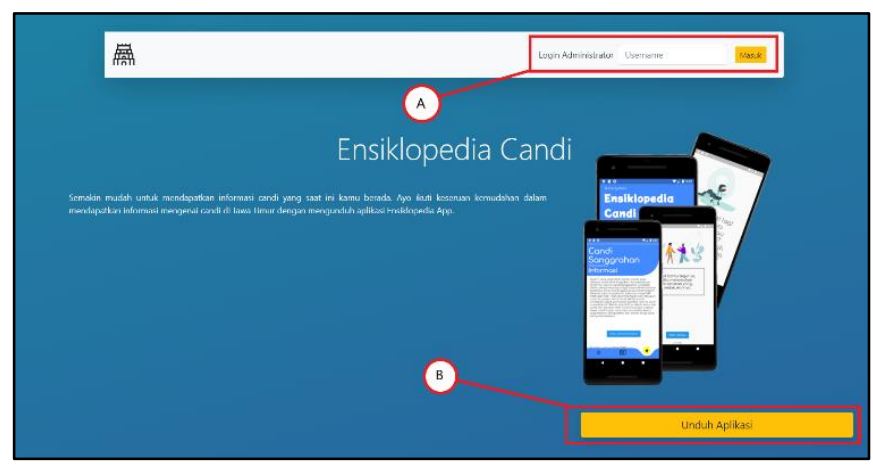

Gambar 5. Halaman landing page aplikasi

Halaman landing page yang seperti pada Gambar 5 dibuat sesenderhana mungkin karena aplikasi pada platform website memang tidak memberikan informasi candi pada pengguna diluar admin, sehingga pengguna hanya akan ditunjukkan tombol pengunduhan aplikasi android seperti pada Gambar 5 (b). Admin dapat langsung memasukkan username pada kolom Login Administrator seperti Gambar 5 (a).

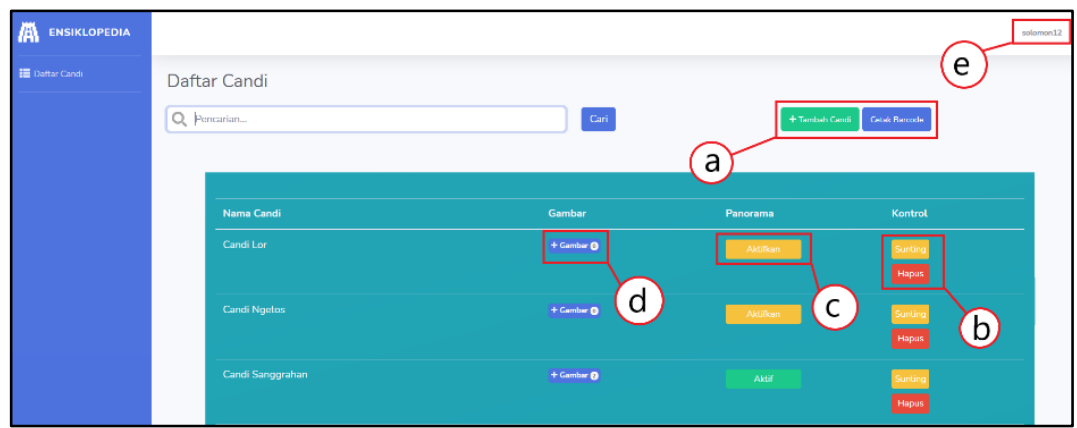

Gambar 6. Halaman Dashboard Aplikasi

Halaman Dashboard ini dapat diakses melalui autentikasi data admin pada basis data, pada laman ini admin akan ditampilkan sebuah tabel dari nama candi - candi yang telah diinputkan. Admin dapat menambah candi baru atau mencetak semua qrcode milik candi yang ditunjukkan pada Gambar 6 (a). Adapun informasi ataupun data candi juga dapat dihapus maupun disunting melalui tombol yang ditunjukkan pada Gambar 6 (b).

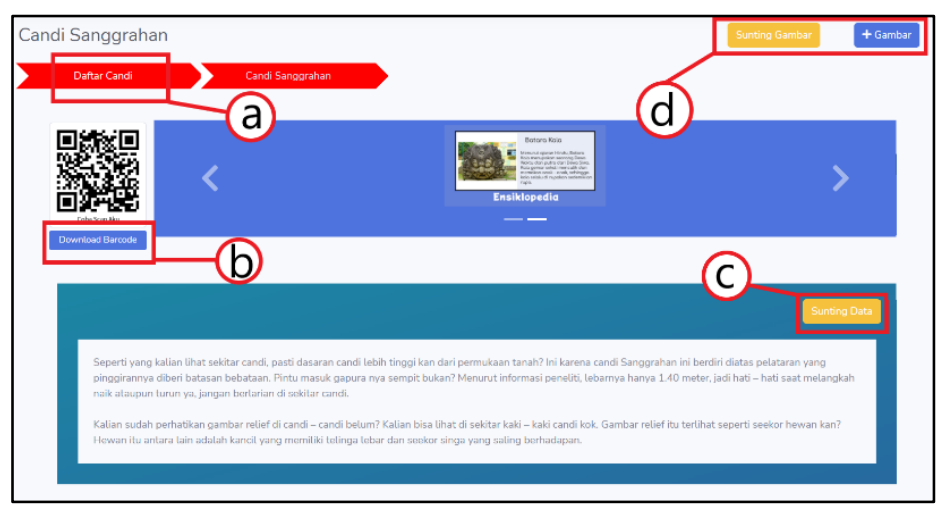

Gambar 7. Halaman Detail Candi

Halaman Detail Candi ini merupakan tampilan dari informasi yang telah ditambah oleh admin melalui halaman dashboard seperti pada Gambar 6. Informasi yang ditampilkan pada Gambar 7 tersebut nantinya akan dikirimkan ke aplikasi pada platform android melalui sebuah kode unik yang telah dienkripsi ke qrcode yang dapat dicetak melalui tombol seperti pada Gambar 7 (b) untuk kemudian dipindahi melalui aplikasi dengan platform android.

(2) Antarmuka perangkat lunak pada platform android.

Adapun antarmuka yang dihasilkan melalui pengembangan aplikasi Ensiklopedia Candi ini yang diantaranya. 
Procedia of Engineering and Life Science Vol. 1. No. 1 March 2021

Seminar Nasional \& Call Paper Fakultas Sains dan Teknologi (SENASAINS 1st)

Universitas Muhammadiyah Sidoarjo

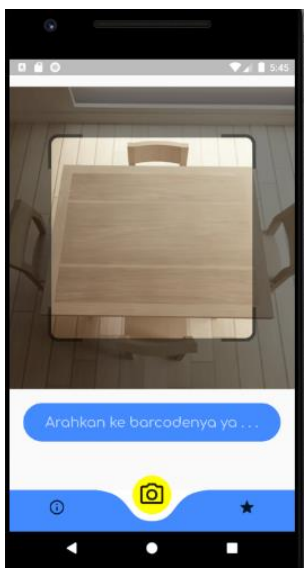

Gambar 8. Tampilan Utama Aplikasi

Pada tampilan utama aplikasi Ensiklopedia Candi ini pengguna bisa langsung mengarahkan kamera pada qrcode yang merupakan milik candi tertentu untuk seterusnya akan di deskripsikan. Aplikasi akan otomatis memindahkan tampilan jika pengambilan data informasi candi telah selesai.

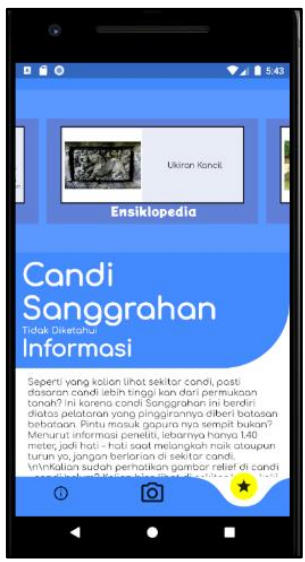

Gambar 9. Tampilan Hasil Aplikasi

Tampilan hasil aplikasi akan memuat informasi yang telah dikirimkan melalui hasil deskripsi qrcode yang kemudian meminta request ke aplikasi platform website. Aplikasi pada platform website akan mengirim kode salah jika hasil dari deskripsi aplikasi tidak ditemukan pada basis data, aplikasi pada platform android akan merespon kode salah tersebut ke tampilan hasil kosong seperti pada Gambar 10.

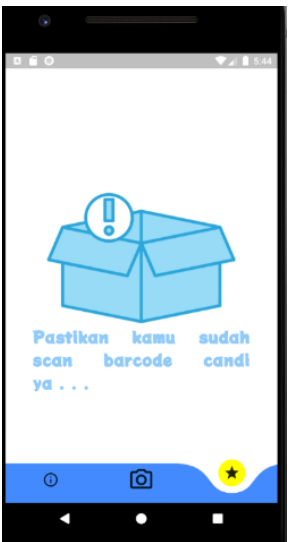

Gambar 10. Tampilan Hasil Kosong pada Aplikasi 


\section{KESIMPULAN}

Berdasarkan dari hasil analisis, dan pengimplementasian Aplikasi Ensiklopedia Candi Berbasis Android ini, dapat disimpulkan sebagai berikut : (1) Aplikasi baik pada platform website dan android telah dikembangkan sesuai dengan harapan peneliti, baik dari segi fungsional maupun non-fungsional. (2) Aplikasi Ensiklopedia Candi tetap perlu menggunakan jaringan internet untuk mendapatkan informasi yang berasal dari aplikasi website, sehingga pengelola candi perlu memberikan akses internet atau pengguna perlu memiliki akses internet sebelum menggunakan aplikasi. (3) Aplikasi Ensiklopedia Candi ini di kembangkan menggunakan beberapah bahasa pemrograman antara lain seperti : (a) PHP. (b) HTML. (c) CSS. (d) Javascript. (e) Dart.

Adapun saran yang dimaksudkan untuk pengembangan lebih lanjut mengenai Aplikasi Ensiklopedia Candi Berbasis Android ini sebagai berikut : (1) Penambahan fitur akun untuk menyimpan riwayat perjalanan pengguna dengan memanfaatkan akun dari gmail. (2) Penambahan informasi pada candi seperti video singkat dan juga denah dari candi terkait.

\section{REFERENSI}

[1] C. F. Yusuf, Dinamika Islam Filipina, Burma, dan Thailand, Jakarta:Pusat Penelitian dan Pengembangan Lektur dan Khazanah, 2015.

[2] E. Sedyawati, H. Santiko, H. Djafar, R. Maulana, W. D. S. Ramelan dan C. Ashari, Candi Indonesia : Seri Jawa, Jakarta: Kementrian Pendidikan dan Kebudayaan, 2013.

[3] Ida Bagus Agung Manuaba, I Made Agus Wirawan dan I Gede Mahendra Darmawiguna, "Pengembangan Aplikasi E-Museum Berbasis Android Menggunakan Jaringan Semantik" Senapati Prosiding Seminar Nasional Pendidikan Teknik Informatika, pp. 310-317, Agustus 2016. 